\title{
Hospital based palliative care in sub-Saharan Africa; a six month review from Malawi
}

\author{
Julia B Tapsfield ${ }^{1^{*}}$ and M Jane Bates ${ }^{2^{*} \dagger}$
}

\begin{abstract}
Background: The World Health Organisation recognises the importance of palliative care in an African setting. Despite this services are often patchy and inconsistent, and many operate at health centre and/or community level. Few reports from hospital based palliative care services in sub-Saharan Africa exist in the current literature. As part of its activities Tiyanjane Clinic has been providing hospital based palliative care to patients at Queen Elizabeth Central Hospital, a large government tertiary referral institution, in the Southern region of Malawi since 2003, caring for patients with HIV, cancer and other non-malignant palliative diagnoses.
\end{abstract}

Methods: A retrospective review of case notes for all in-patients seen by Tiyanjane Clinic over a six month period (April-Sept 2009) was undertaken.

Results: A total of 177 patients were seen, for whom 137 case notes were available (77\%). 58\% of patients were male, $42 \%$ female. The average age of patients was 39.1 years (range 15-92 years). 54\% of patients were HIV positive, with $34 \%$ on ARV drugs at the time of care. $42 \%$ of patients had HIV related diagnoses, including AIDS defining malignancies, 48\% had (non AIDS related) cancers and 9\% had other palliative diagnoses. The mean age of patients with HIV related diagnoses was 34 years, for cancer patients it was 48 years. Pain was the most commonly reported symptom (74\%), with $56 \%$ of patients requiring oral morphine. The mean daily dose of morphine was $30 \mathrm{mg} /$ day (range $9-100 \mathrm{mg}$ ). 65\% of patients were discharged home, 26\% of patients died during admission.

Conclusions: The palliative care population in this setting is relatively young, especially among patients with HIV related diagnoses. HIV and cancer are the main diagnostic groups. Pain is the most commonly reported symptom, with oral morphine frequently required. Health workers require access to and knowledge of oral morphine in order to provide appropriate assistance to patients under their care.

\section{Background}

Palliative care improves the quality of life for patients and families who face life-threatening illnesses, from diagnosis through to end of life and bereavement [1]. In the developing world the majority of cancer patients present at an advanced stage of disease making palliative care an essential part of management [2]. Palliative care has also been shown to play a critical role in the management of other chronic conditions, including HIV and AIDS, even in places where anti-retroviral drugs (ARVs)

\footnotetext{
* Correspondence: j.tapsfield@doctors.org.uk; j.bates@malawi.net

+ Contributed equally

'Estcourt Provincial Hospital, Old Main Road, Estcourt 3310, KwaZulu-Natal, South Africa

${ }^{2}$ Tiyanjane Clinic, Queen Elizabeth Central Hospital, PO Box 95, Blantyre, Malawi

Full list of author information is available at the end of the article
}

are available $[3,4]$. Despite recognition from the World Health Organisation (WHO) of the importance of providing palliative care, studies show that the service provision in Africa remains patchy and inconsistent [5-7].

Tiyanjane Clinic was established in 2003 with the aim of improving the quality of life of patients at Queen Elizabeth Central Hospital (QECH), the largest government hospital in Malawi with over 1200 beds, and the surrounding communities. Malawi is one of the most resource poor countries in sub-Saharan Africa (SSA), with around one million of its population living with HIV and an estimated $40 \%$ of the population living in extreme poverty [8]. Per capita spending on health is around $\$ 64$ per year [9]. These problems are exacerbated by critical human resource shortages in the health care sector [10]. 
Starting with a focus on providing holistic care for patients with HIV and AIDS related illnesses Tiyanjane Clinic provides palliative care services for in-patients referred from the adult medical wards at QECH. The clinic is situated within the hospital and referrals are taken from clinicians working on those wards using a structured referral form. Other aspects of the service, not reported on here, include HIV counseling and testing, out-patient clinics, community visits and a community based service at a nearby government run health centre. The Clinic team comprises three clinicians, three nurses, one HIV counselor and two support staff. Government health services, through the hospital, district health services and the local medical school, support the majority of the costs.

This review looks at six months of in-patient palliative care services at Tiyanjane Clinic.

\section{Methods}

A retrospective paper based case-notes review of inpatients managed by Tiyanjane Clinic over a six month period (April - September 2009) was undertaken. An ethics waiver from the University of Malawi, College of Medical Research and Ethics was obtained to perform our study. Clinic records were used to generate a list of all inpatients at QECH who were seen by Tiyanjane over this time period. There were no exclusion criteria with all patients seen over this time period included in the study. Initially paper notes, the principle source of patient records, and then the clinic's computer database were searched to obtain comprehensive records for each patient. Each set of notes was used to identify data on patient age, sex, diagnosis, reported symptoms, medications prescribed, length of stay and outcome. All records were anonymous for identifying patient details. The data was recorded in and analysed using Microsoft Excel.

\section{Results}

A total of 177 patients were seen over a six month period. Records were obtained for 137 of these patients (77\%), with the remaining 40 patient's records unobtainable. Of these 137 there were 17 patients (12\%) for whom only computer records were available.

79 patients were male (58\%) and 58 were female (42\%). The mean age of the patients was 39.1 years (range 15 92 years). 74 patients (54\%) were known to be HIV positive, with 25 (34\%) already on ARVs at time of care. (Table 1 and 2, Figures 1 and 2)

66 patients $(48 \%)$ had a diagnosis of (non-AIDS related) cancer. 40 patients (29\%) had an AIDS defining malignancy (as defined by the WHO clinical staging of HIV/AIDS for adults and adolescents [11]), mainly Kaposi's sarcoma (37patients). 18 (13\%) had other diagnoses related to HIV, including cryptoccocal meningitis,
Table 1 Patient sex ratios

\begin{tabular}{lcccccccc}
\hline & All pts & (\%) & HIV pts & (\%) & Cancer pts & (\%) & Other pts & (\%) \\
\hline Sex & & & & & & & & \\
\hline Male & 79 & 58 & 33 & 57 & 40 & 61 & 6 & 46 \\
\hline Female & 58 & 42 & 25 & 43 & 26 & 39 & 7 & 54 \\
\hline Total & 137 & 100 & 58 & 100 & 66 & 100 & 13 & 100 \\
\hline
\end{tabular}

lactic acidosis secondary to ARVs, "advanced HIV" and progressive multifocal leukoencephalopathy, giving a total of 58 patients (42\%) with HIV related diagnoses. The remaining 13 patients (9\%) had other palliative diagnoses, including heart failure and/or cardiomyopathy (4 patients), liver and/or renal failure ( 2 patients) and subarachnoid haemorrhage (2 patients). (Figure 3 )

The mean age of patients with HIV related diagnoses was 34 years (range 15-53). For cancer patients the mean age was 48 years (range 15-92). (Figure 1)

Pain was the most commonly reported symptom (74\%). Other common symptoms were shortness of breath (50\%), being unable to walk (44\%) and weakness (37\%). Four patients (3\%) reported symptoms of anxiety/depression. $83 \%$ of cancer patients reported pain, $71 \%$ of those with HIV related diagnoses reported pain. (Figure 4)

Analgesic drugs were prescribed to 117 of the patients (85\%) during admission. 77 patients (56\%) were prescribed oral morphine (liquid and/or tablets). The mean total daily dose of morphine was $30 \mathrm{mg}$ (range of $9-100 \mathrm{mg}$ ). 64\% of cancer patients were prescribed morphine; mean daily dose $34.0 \mathrm{mg}$ (range $15-100 \mathrm{mg}$ ). $52 \%$ of patients with HIV related diagnoses were prescribed morphine, mean daily dose $25.5 \mathrm{mg}$ (range 9-60 mg).

The average length of involvement by the palliative care team was 6.3 days (range 1-39 days). 89 patients (65\%) were discharged home and 36 (26\%) died on the ward. $33 \%$ of the patients with HIV related diagnoses died on the ward, $23 \%$ of cancer patients died on the ward. Follow-up was planned for 45 patients (51\% of those discharged), with 26 of these patients actually attending. An additional 10 patients for who arranged follow-up wasn't documented were also seen again by clinic, making a total of 36 patients (40\% of those discharged) followed-up after discharge. (Table 3 and 4)

\section{Discussion}

This case note review provides a good insight into a hospital based palliative care service in a low resource setting, with a high HIV prevalence, in SSA. Palliative care has recently been recognised by the Ministry of Health in Malawi as part of a minimum standard of care for all tertiary institutions (Dr Jane Mallewa, QECH, personal communication). This paper provides useful data of some of the service needs that would 
Table 2 HIV status of patients

\begin{tabular}{|c|c|c|c|c|c|c|c|c|}
\hline & All pts & (\%) & HIV pts & (\%) & Cancer pts & (\%) & Other pts & (\%) \\
\hline Negative & 44 & 32 & 0 & 0 & 37 & 56 & 7 & 54 \\
\hline Positive & 74 & 54 & 58 & 100 & 13 & 20 & 3 & 23 \\
\hline Unknown & 19 & 14 & 0 & 0 & 7 & 23 & 3 & 11 \\
\hline \multicolumn{9}{|c|}{ HIV pts on ARVs? } \\
\hline On ARVs & 25 & 34 & 38 & 66 & 5 & 38 & 3 & 100 \\
\hline Not on ARVs & 46 & 62 & 17 & 29 & 8 & 62 & 0 & 0 \\
\hline Unknown & 1 & 1 & 1 & 2 & 0 & 0 & 0 & 0 \\
\hline Stopped & 2 & 3 & 2 & 3 & 0 & 0 & 0 & 0 \\
\hline
\end{tabular}

need to be considered when developing such a service in the same or similar settings.

The mean age of in-patients seen by the palliative care team was 39.1 years; the average life expectancy in Malawi is 53 years [12]. Other studies of palliative care populations from around the world have found a mean age of 66 years in the UK, a median of 62 years in Taiwan and a mean of 42.7 years from a hospital based palliative care service in South Africa, highlighting the lower age range which maybe expected by those providing palliative care in SSA [13-15]. The difference in age between the patients with HIV related diagnoses and cancer patients (33 years compared with 48 years) emphasises the impact of the HIV epidemic in our setting. Patients are being referred to palliative care services during what should be expected to be their most productive working years. This places a particular burden on families and has implications for patients and carers alike.

It is important to note however that more than one in five of the patients seen were either over the age of 60 $(12 \%)$ or under the age of $25(11 \%)$. Health care professionals need to be aware of the special needs and perspectives of both adolescents and young adults, and the elderly facing life threatening illnesses in this setting.

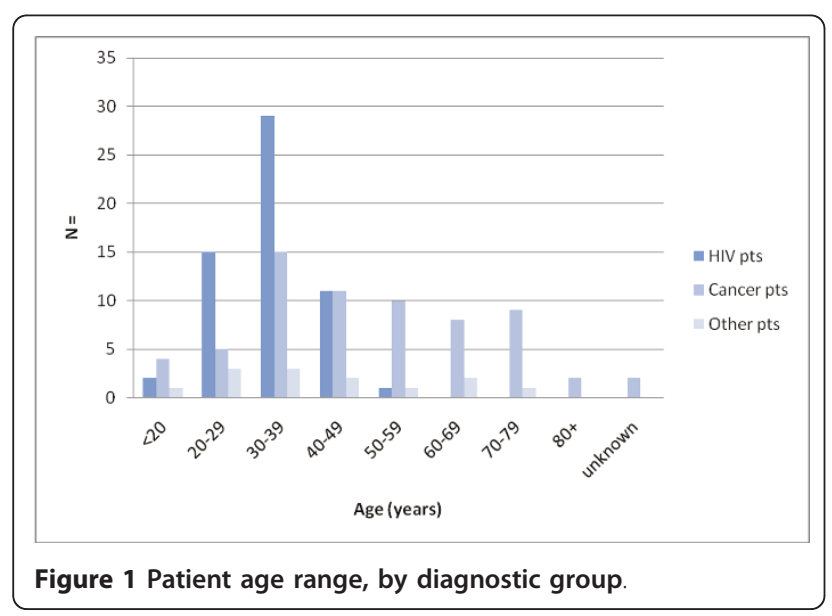

At the time of review referrals were predominately taken from general medical adult wards. More recently an outreach service to general surgical, gynaecology and other specialist wards in the hospital is being developed utilising a series of 'link nurses' based on the specialist wards who are trained to undertake palliative care assessments. There is a separate paediatric palliative care team operating at the hospital. The total number of patients requiring palliative care across all hospital specialties at our hospital during this period is likely to have been much higher.

HIV was common, with just over half of the patients HIV positive. Malawi has an HIV prevalence of $11.9 \%$, although the urban prevalence is known to be higher at around 17\% [16]. Recent studies in QECH have found an HIV prevalence of $70 \%$ among medical in-patients [17]. Only a third of the HIV positive patients were on ARVs. Reasons for patients not being on ARVs when being seen by the palliative care team may include this presentation being their first presentation of disease, and therefore the initial diagnosis of HIV, or the presence of other co-morbidities, such as TB, delaying the initiation of ARVs until a later date. ARVs have been freely available in the public sector in Malawi since 2004 , with an estimated 300,000 people eligible. Currently around 200,000 are on treatment [18]. More work

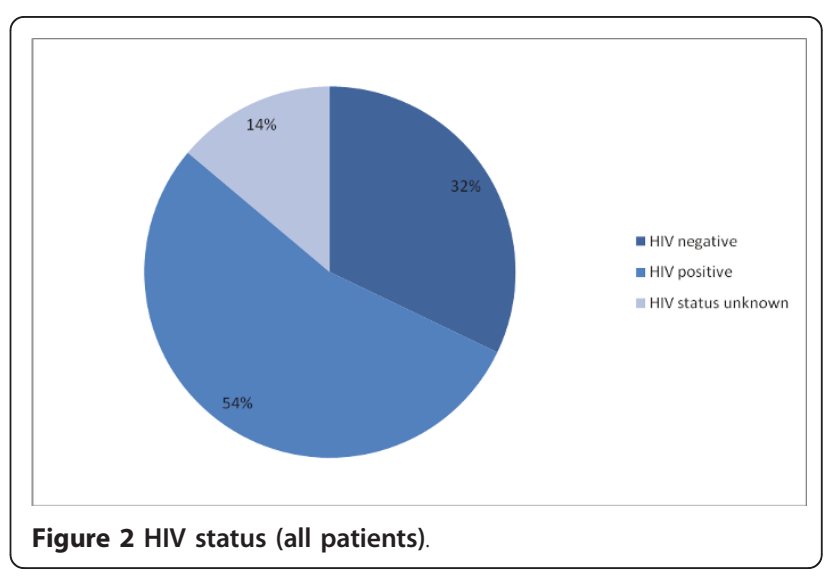




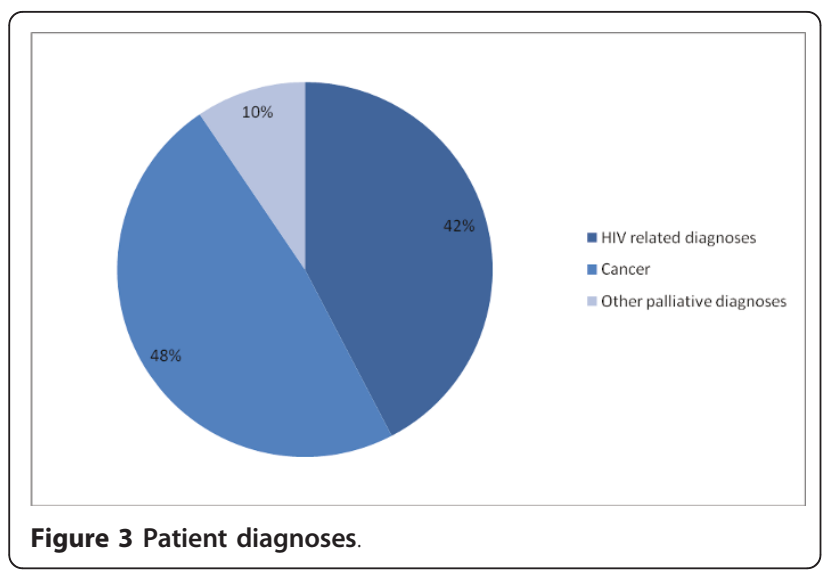

to improve awareness of, and access to, ARVs in Malawi is still needed to further increase the number of eligible people receiving ARVs. However it is important to emphasize that palliative care services may still be required for patients with HIV who are taking ARVs, especially for those who have treatment related side effects, poor adherence or HIV related malignancies.

There was a high prevalence of pain among patients with cancer $(83 \%)$ and with HIV related diagnoses (71\%). Other symptoms were also common among both sets of patients, which is consistent with previous findings that symptoms among HIV/AIDS patients are similar to those of patients with terminal cancer [19]. 56\% of patient's required oral morphine. The mean daily dose of morphine prescribed by palliative care personnel in this setting, $30 \mathrm{mg} /$ day, was much lower than the average dose of 100-250 mg/day found by a 2007 Cochrane review of opiate prescribing in palliative care [20]. Reasons for the lower doses are not clear and are likely to be multi-factorial. Despite the fact that it has repeatedly be shown to be safe and cost effective to use

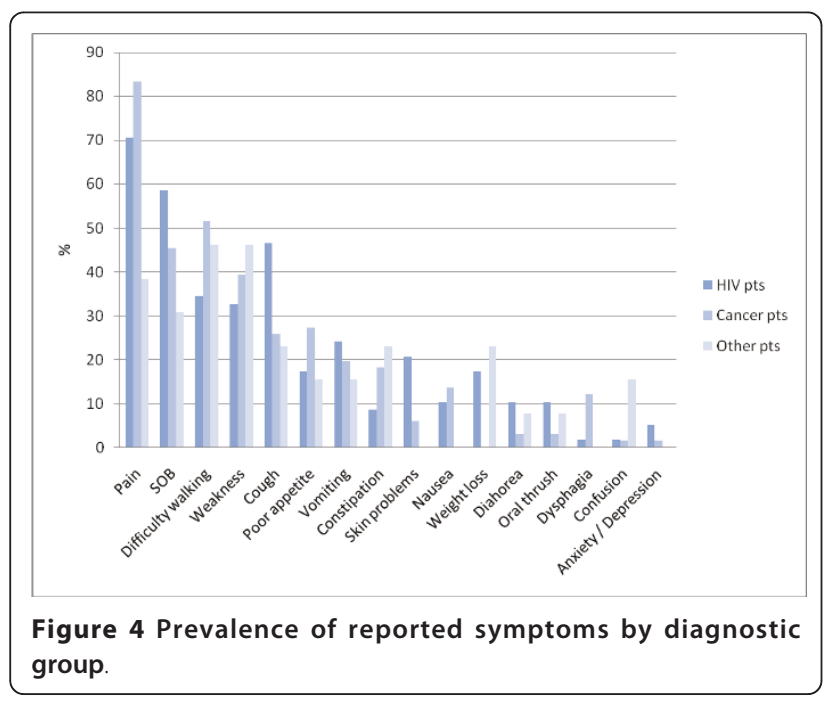

Table 3 Patient outcomes

\begin{tabular}{lcccccccc}
\hline & $\begin{array}{c}\text { All } \\
\text { pts }\end{array}$ & (\%) & $\begin{array}{c}\text { HIV } \\
\text { pts }\end{array}$ & (\%) & $\begin{array}{c}\text { Cancer } \\
\text { pts }\end{array}$ & $\begin{array}{c}\text { (\%) } \\
\text { Other } \\
\text { pts }\end{array}$ & (\%) \\
\hline Discharged & 89 & 65 & 29 & 50 & 49 & 74 & 11 & 85 \\
\hline Died & 36 & 26 & 19 & 33 & 15 & 23 & 2 & 15 \\
\hline Unknown & 12 & 9 & 10 & 17 & 2 & 3 & 0 & 0 \\
\hline
\end{tabular}

in low resource setting, with negligible rates of iatrogenic addiction, morphine is underutilised in numerous low resource settings $[7,21]$. Reasons for this include restrictive legislation, drug availability, lack of training, and fears over addiction and dependence [6,22].

A short mention should be made regarding symptoms of anxiety and depression. According to our results these symptoms were only reported by 4 patients. Other studies estimate that between $7 \%$ and $30 \%$ of palliative patients suffer from depression [23,24]. HIV patients in South Africa were found to exhibit high levels of psychological symptoms, with $55 \%$ of patients reporting depression and $49 \%$ anxiety [25]. There is little recognition of, and in-fact no word in Chichewa, the local language in Malawi, for depression. Whether our findings represent a true lack of symptoms or reflect under reporting in our records is not clear. Further work into evaluating psychological symptoms among our patient population using more in-depth screening tools would be helpful to address whether we are adequately screening for, and therefore responding appropriately to, these symptoms.

Hospital in-patient stays were short (mean 6.3 days). Ongoing provision of holistic care in the community is therefore vital, with family members, community home based care teams and community leaders all playing their part. Through collaboration with NGOs and community based organisations the Ministry of Health in Malawi has a clear system for training of home based care volunteers, and numerous groups operate in all regions of the country. Our programme works with over 100 community based volunteers in a nearby township area to provide ongoing care after discharge from hospital. Programmes such as the integrated community based home care (ICHC) models from South Africa [7] provide some ideas as to how such programmes may be implemented, though the dramatic paucity of resources for health care and of human resource in Malawi may limit replication.

Only $40 \%$ of patients discharged were followed up by the palliative care team. Transport has been cited by others as a major barrier in access to health services in resource poor settings [26]. As a central teaching hospital patients are often referred from distant health facilities far from the clinic. There is no government system of welfare payments to support palliative care patients in Malawi, with loss of income due to disease meaning funds for transport to attend follow-up, along with 
Table 4 Follow-up (FU) of discharged patients

\begin{tabular}{lcccccccc}
\hline & All pts & (\%) & HIV pts & (\%) & Cancer pts & (\%) & Other pts & (\%) \\
\hline Planned FU & 45 & $57^{*}$ & 18 & $36 \%^{*}$ & 23 & $47 \%^{*}$ & 4 & $36 \%^{*}$ \\
\hline Planned FU attended & 26 & $58^{* *}$ & 9 & $50^{* *}$ & 15 & $65^{* *}$ & 2 & $50^{* *}$ \\
\hline Non-planned FU attended & 10 & $11^{*}$ & 2 & $7^{*}$ & 7 & $14^{*}$ & 1 & $9^{*}$ \\
\hline Total attending FU & 36 & $40^{*}$ & 11 & $22^{*}$ & 22 & $30^{*}$ & 3 & $27^{*}$ \\
\hline
\end{tabular}

* \% of people who were discharged

** \% of people for whom FU was planned.

many other things, may be significantly lacking. Palliative care training at district and health centre level is vital to assist with timely and appropriate follow-up for patients in this setting.

\section{Limitations}

This was a retrospective study. Despite careful searching $23 \%$ of data sheets (either in the computer or paper based clinic systems) were not found. Prospective data collection could have avoided this problem.

It is beyond the remit of a case note review to address the efficacy and quality of these interventions. Qualitative research concentrating on patients, and their families, experiences of the care they receive is needed to determine how care impacts upon the quality of life of users, and to help develop the service offered in response to these findings.

\section{Conclusions}

This study provides insight into the problems faced by palliative care in- patients in a low resource, high HIV prevalence setting. Palliative care patients are younger than in settings of low HIV prevalence and many are taking ARV medications for HIV. Cancer and HIV/ AIDS are the main diagnostic groups. Pain is a common symptom. Oral morphine is required frequently, but at relatively low doses, to control pain. Rates of depression are poorly recorded in routine assessments. Difficulties in following-up patients after discharge mean that outreach support and training of staff in district areas to provide palliative care is important to increase access to all patients in need of palliative care services.

\section{Abbreviations}

HIV: Human immunodeficiency virus; AIDS: Acquired immunodeficiency disease; ARVs: Anti-retroviral therapy; WHO: World Health Organisation; QECH: Queen Elizabeth Central Hospital (Blantyre, Malawi); SSA: Sub-Saharan Africa; ICHC: Integrated community based home care.

\section{Acknowledgements}

No acknowledgments.

\section{Author details}

${ }^{1}$ Estcourt Provincial Hospital, Old Main Road, Estcourt 3310, KwaZulu-Natal, South Africa. ${ }^{2}$ Tiyanjane Clinic, Queen Elizabeth Central Hospital, PO Box 95, Blantyre, Malawi.

\section{Authors' contributions}

MJB came up with the idea for the study and oversaw the project and drafting of the manuscript. JBT carried out the data collection and analysis and drafted the manuscript. Both authors read and approved the final manuscript.

\section{Competing interests}

The authors declare that they have no competing interests.

Received: 2 February 2011 Accepted: 9 July 2011 Published: 9 July 2011

\section{References}

1. $\mathrm{WHO}>$ programmes and projects $>$ cancer $>$ palliative care. [http://wwW. who.int/cancer/palliative/en/].

2. Lingwood RJ, Boyle P, Milburn A, Ngoma T, Arbuthnott J, McCaffery R, Kerr SH, Kerr DJ: The challenge of cancer control in Africa. Nature Reviews Cancer 2008, 8:398-403.

3. Selwyn PA: Why should we care about palliative care for AIDS in the era of antiretroviral therapy? Sexually transmitted infections 2005, 81:2-3.

4. Collins K, Harding R: Improving HIV management in sub-Saharan Africa: How much palliative care is needed? AIDS Care 2007, 19(10):1304-1306.

5. Harding R, Higginson IJ: Palliative care in sub-Saharan Africa. Lancet 2005, 365:1971-77.

6. Harding R, Stewart K, Marconi K, Higginson IJ: Current HIV/AIDS end-of-life care in sub-Saharan Africa. BMC Public Health 2003, 3:33.

7. Clark D, Wright M, Hunt J, Lynch T: Hospice and palliative care development in Africa: A multi-method review of services and experiences. Journal of pain and symptom management 2007, 33(6):698-710.

8. DFID Measuring poverty in Malawi. 2009 [http://www.dfid.gov.uk/MediaRoom/Case-Studies/2010/Measuring-Poverty-in-Malawi/].

9. WHO: Epidemiological fact sheet on HIV and AIDS; care data on epidemiology and response Malawi. 2008 [http://apps.who.int/ globalatlas/predefinedReports/EFS2008/full/EFS2008_MW.pdf], Update October 2008

10. WHO: Country case study; Malawi's emergency human resources programme 2008 (GHWA). 2008 [http://www.who.int/workforcealliance/ about/taskforces/education_training/case_studies/en/index.html].

11. Revised WHO clinical staging of HIV/AIDS for adults and adolescents: WHO/HIV/2005.02. [http://whqlibdoc.who.int/hq/2005/WHO_HIV_2005.02. pdf].

12. UNICEF Malawi Statistics, basic indicator. [http://www.unicef.org/ infobycountry/malawi_statistics.html].

13. Potter J: Symptoms in $\mathbf{4 0 0}$ patients referred to palliative care services: prevalence and patterns. Palliative Medicine 2003, 17:310-314.

14. Tsai JS, Wu CH, Chiu TY, Hu WY, Chen CY: Symptom patterns of advanced cancer patients in a palliative care unit. Palliative Medicine 2006, 20(6):617-22.

15. Jameson C: The role of palliative care inpatient unit in disease management of cancer and HIV patients. South African Medical Journal 2007, 97:849-852.

16. USAID Malawi HIV/AIDS health profile. [http://www.usaid.gov/our_work/ global_health/aids/Countries/africa/malawi_profile.pdf].

17. Kumwenda JJ, Mateyu G, Kampondeni S, Van Dam AP, Van Lieshout L, Zijlstra EE: Differential diagnosis of stroke in a setting of high HIV prevalence in Blantyre, Malawi. Malawi Medical Journal 2005, 17(4):107-11. 
18. UNAIDS; Malawi HIV and AIDS Monitoring and Evaluation Report: 20082009 UNGASS. [http://data.unaids.org/pub/Report/2010/malawi_2010_ country_progress_report_en.pdf].

19. Solano JP, Gomes B, Higginson IJ: A comparison of symptom prevalence in far advanced cancer, AIDS, heart disease, chronic obstructive pulmonary and renal disease. Journal of pain and symptom management 2006, 31(1):58-69.

20. Wiffen PJ, McQuay HJ: Oral Morphine for cancer pain. Cochrane Database of Systematic Reviews 2007, 4:CD003868.

21. Logie $D$, Leng $M$ : Africans die in pain because of fears of opiate addiction. BMJ 2007, 335(7622):685.

22. Porter J, Jick H: Addiction rare in patients treated with narcotics. New England Journal of Medicine 1980, 302(2):123.

23. Akechi T, Okuvanga T, Sugawara Y, Shima Y, Furukawa T: Screening for depression in terminally ill cancer patients in Japan. Journal of pain and symptom management 2006, 31:5-12.

24. Lloyd-Williams M, Shiels C, Dowrick C: The development of the Brief Depression Scale (BEDS) to screen for depression in patients with advanced cancer. Journal of affective disorders 2007, 99:259-264.

25. Peltzer K, Phaswana-Mafaya $\mathrm{N}$ : The spymtom experience of people living with HIV and AIDs in the Eastern Cape, South Africa. BMC health services research 2008, 8:271.

26. Rosen S, Ketthapile M, Sanne I, DeSilva MB: Cost to patients of obtaining treatment for HIV/AIDS in South Africa. South African Medical Journal 2007, 97(7):524-29.

Pre-publication history

The pre-publication history for this paper can be accessed here: http://www.biomedcentral.com/1472-684X/10/12/prepub

doi:10.1186/1472-684X-10-12

Cite this article as: Tapsfield and Jane Bates: Hospital based palliative care in sub-Saharan Africa; a six month review from Malawi. BMC Palliative Care 2011 10:12.

\section{Submit your next manuscript to BioMed Central and take full advantage of:}

- Convenient online submission

- Thorough peer review

- No space constraints or color figure charges

- Immediate publication on acceptance

- Inclusion in PubMed, CAS, Scopus and Google Scholar

- Research which is freely available for redistribution

Submit your manuscript at www.biomedcentral.com/submit
Biomed Central 